\title{
Fertility preferences: \\ what measuring second choices teaches us
}

\author{
Saskia Hin, Anne Gauthier, Joshua Goldstein and Christoph Bühler*
}

\begin{abstract}
This article aims to strengthen the research methodology for studies of fertility preferences. Knowledge of personal fertility ideals is important both for demographers and policy makers, but the measurement techniques currently employed are not very refined. We suggest that the information provided by asking people about their personal ideal number of offspring can be improved in quality when asking them to also consider alternative preferences. The results of a survey conducted in the Netherlands demonstrate how measuring second (and, if desired, further) choices improves our ability to differentiate between different population subgroups. Moreover, it brings to light individuals' openness to their 'second best ideals'. Including questions on alternative ideals in surveys thus enhances the qualitative potential of studies on fertility ideals and adds a new dimension to research on the how and why of fertility gaps between desired and achieved fertility.
\end{abstract}

\section{Introduction: why fertility ideals again?}

For decades, questions on fertility ideals have been routinely included in scientific surveys in many countries (for an early overview, see Stoezel 1954, Table 1). The study of reproductive ideals started in the late 1930s. It was based on the idea that people's preferences have a predictive value and might tell us how many children they would eventually have (Philipov and Bernardi, forthcoming). However, as fertility ideals seemed to be unable to predict trends in fertility behaviour

\footnotetext{
* Saskia Hin, Max Planck Institute for Demographic Research (MPIDR), Rostock, Germany. Anne Gauthier, Netherlands Interdisciplinary Demographic Institute (NIDI), The Hague, The Netherlands.

Joshua Goldstein (correspondence author), Max Planck Institute for Demographic Research MPIDR), Konrad-Zuse-Strasse 1, 18057 Rostock, Germany. Email: goldstein@demogr.mpg.de Christoph Bühler, Leibniz Universität Hannover, Institute of Sociology, Hannover, Germany.
} 
(including the end of the post-war baby boom), demographers lost interest in them (Trent 1980).

In recent years, we have witnessed a 'comeback' of fertility ideals, both in the public domain and in demographic research. One reason for this development might be the fact that contemporary Europe is faced with 'ageing societies', which are characterised by low fertility behaviour while at the same time displaying persistent 'high' fertility ideals (i.e. above replacement level) (see e.g. Dey and Wasoff 2010). In particular policy makers who worry about declining fertility see the persistence of high ideals as a window of opportunity and justification for attempts to close the gap between fertility ideals and fertility behaviour. The focus on such gaps as a motivation for policy is well illustrated in the European Commission's Green Paper (2005): "Surveys have revealed the gap which exists between the number of children Europeans would like (2.3) and the number that they actually have (1.5). (...) if appropriate mechanisms existed to allow couples to have the number of children they want, the fertility rate could rise overall (...)."

Whether or not there is a fertility gap and whether or not the existence of fertility gaps is a legitimate justification for pro-natalist policies is beyond the scope of this paper. The adequate measurement of fertility ideals may, however, contribute to such discussions by providing insight into the strength of people's personal fertility ideals and their openness to 'alternatives'.

The concept of fertility ideals has also re-emerged in the academic literature. Recent studies (e.g. Goldstein et al. 2003, p. 480) suggest that ideal and actual fertility have both decreased and display similar trends despite the fact that they are not at even levels. This is a good reason for studying ideals. Even if they might not adequately predict actual fertility levels, they may tell us something about directional trends.

The relationship between ideals and actual fertility (Bongaarts 2001) turns the measurement of ideals into a valuable instrument for demographers who want to compare fertility patterns across countries. Fertility ideals have the potential to explain differences in childbearing in and beyond Europe. Insight into fertility ideals furthers our understanding of the specificities of reproductive cultures in industrial societies, where the widespread availability of reliable means of birth control coincides with a wide range of fertility outcomes. In addition, the study of fertility ideals sheds light on variations in the ideal number of children between different subgroups within our societies. If different types of people are more likely to prefer different numbers of offspring, knowledge of the profile and prevalence of these types within societies may prove to be a powerful tool for predicting the response rates to specific pro-natalist policies (see Hakim 2011).

Studies on fertility ideals, however, face a major empirical problem. Although actual fertility has dropped well below replacement level in many countries, stated ideal fertility continues to focus on two children. In surveys, many respondents say they prefer to have two children: This category frequently 
encompasses between 40 and 60 per cent of all respondents (Van de Kaa 2001, p. 318). This pattern might be due to an actual mismatch of ideal and actual fertility, in which the ideal number of offspring is well above that of the actual one. However, high fertility ideals could also be an artefact of imprecise measurement, in which 'two' is simply an expression of indecision or 'I don't know'. The social undesirability of answers that substantially deviate from the social norm (i.e. families with two children) may also lead people to say they would prefer to have two children. Because studies on fertility ideals ask people to state only one single ideal family size, so far it is impossible to determine which of the two outlined causes underlies the patterns observed in empirical studies. In order to analyse how attached people are to their stated ideal, we need to know their alternative preferences. Gathering this information can help us determine which alternative numbers of offspring they might also perceive as desirable.

Our article presents the findings of an empirical study carried out in the Netherlands that included people's second to fourth fertility preference in addition to their ideal number of children. By presenting the results of a more sophisticated method for measuring the ideal number of offspring we aim to invigorate research on fertility ideals and to improve its methodological strength. We find that using a measurement method which includes people's second and up to fourth preferences for offspring numbers refines our understanding of broader social norms and personal beliefs about fertility as well as their variance between groups.

\section{Background framework}

\subsection{Concept}

Our article uses 'fertility ideals' and 'fertility preferences' interchangeably as both concepts intend to capture individuals' personal perceptions on ideal family size. In order to measure these concepts empirically, question wordings specify that respondents should state their personal preferred number of children. Defined as such, 'fertility ideals' primarily reflect individual motivations, attitudes and beliefs. They express personal evaluations of formulated objectives (Miller 1994; Bühler 2010). Fertility ideals (or preferences or desires) are part of the reproductive decision-making process. They "represent what someone wishes for or wants" (Miller 1994, p. 228) and provide the motivational basis for behavioural intentions by defining preferred objectives (Perugini and Bagozzi 2001). Sometimes, personal ideals are targeted by questions using 'desire' rather than 'ideal' in their phrasing. These two terms are frequently used interchangeably, 
although it has been suggested that a distinction can be drawn between them (Knodel and Prachuabmoh 1973). ${ }^{1}$

'Fertility ideals' can refer to personal desires as well as to reproductive goals perceived as being socially desirable. It thus has two distinctive meanings and invokes ambiguity when it is not specified. Depending on the exact phrasing of questions, respondents of fertility surveys can interpret them as referring to their own fertility preferences - or instead as capturing their perception of society's ideals, i.e. reproductive goals that are positively valued by society. In the latter case, questions may use wordings such as "Generally speaking, what do you think is the ideal number of children for a family?" (Eurobarometer 2006, question 2, see Testa 2006, p. 151) or "In your opinion, how many children should a married couple have?" (Lightbourne and MacDonald 1982, p. 13). Our survey, however, explicitly focuses on respondents' personal preferences for their own family.

Moreover, the concepts 'fertility ideals' and 'fertility preferences' are distinct from that of 'fertility intentions', which refers to the actual intention or decision to have a child (or an additional child) and the activities planned to reach this goal. In more general terms, individual intentions express " $[\ldots]$ how much an effort (someone) is planning to exert in order to perform the behavior" (Ajzen 1991 , p. 181). In other words, a fertility intention is the outcome of a decisionmaking process, a goal-related plan for action rather than an ideal. Intentions are affected by underlying ideals but are more concrete than the ideals themselves and constrained by reality (Miller 1994; Bühler 2010).

Due to the divergent nature of intentions and preferences, they are empirically addressed in different ways. When respondents are asked about their fertility intentions, questions usually refer to an explicit short-term time framework, for example: "How many children do you intend to have in the next three years?" Respondents are guided towards considering and providing information about concrete planned behaviour. 'Fertility ideals' rather refer to ideal numbers of offspring individuals would ultimately like to have at an unspecified point in their lifespan or to the number those who already completed childbearing would have liked to have. Thus, questions on fertility ideals usually address the desired number of children over the entire reproductive life.

It is uncommon for fertility surveys to include questions on the strength of people's preference for their stated ideal. In our survey, we survey the strength of preference for each stated first, second and third fertility ideal to gain insight into the degree to which people are attached to these ideals and to establish whether there is a hierarchy of reproductive goals. Our concept of 'strength of fertility

Knodel and Prachuabmoh (1973: 620-621) argue that the term 'desire' naturally leads people to consider their personal preferences which take into account their personal situation, since this concept does not prompt them to consider a hypothetical 'ideal conditions' situation. Using 'ideal' in questionnaires would encourage people to consider what their preferences would be under optimal conditions. The authors also argue that, unlike the 'desire' concept, the 'ideal' concept can also be used for studying preferences at the level of societies. 
preference' slightly differs from the concept of 'preference magnitude' used by Terhune and Kaufman (1973) as part of an indicator measuring the utility associated with each family size. We use 'strength of fertility preference' simply to measure the preference distance between two reproductive goals. This measure tells us by how much respondents prefer their first ideal over their second ideal, etc.

\subsection{Previous surveys}

The Gallup polls in the United States started to include questions on preferred family size as early as 1936 by asking people: "What is the ideal size of family? Husband, wife and children" (Gallup and Robinson 1938, p. 394).

Various countries quickly followed (Stoezel 1954) and ideals have been part of research on fertility ever since. Surveys typically tend to force respondents to state one single number of children for their ideal family size. This method has been criticised for several reasons. One of the strongest objections is the fact that it suggests that respondents have definite and unambiguous preferences while, in reality, many of them may not have such a clear ideal (Coombs 1974; Lee 1980; Bühler 2010). Thus, there is an ongoing demand for developing methods permitting researchers to measure fertility ideals with higher precision and sensitivity to variation (Testa and Grilli 2006).

David Goldberg and Clyde Coombs developed an improved methodology to measure ideal family sizes (Goldberg and Coombs 1963), which was also used by Lolagene Coombs in 1974. With the help of the instrument they developed they asked fertile women in Detroit about their alternative fertility preferences in addition to their first preference, thus measuring a hierarchy of preferences between zero and six children. The method was positively referred to in several US studies and adopted by researchers working on developing countries (see e.g. Axinn et al. 1994 on the US; Ahmed 1981 on rural Bangladesh). To the best of our knowledge, however, it seems to have been largely ignored in Europe, with the exception of one reference in a 1981 study on Northern Ireland. It suggested that Coombs' instrument might overcome some of the disadvantages connected with single-point estimates but underlined the experimental stage of the method (Coward 1981, p. 452-453).

Knowledge on the hierarchy of desired family sizes promises to improve the understanding of reproductive ideals and reproductive outcomes in both low and high fertility settings. Alternatively preferred family sizes depict people's general tendencies to have either larger or smaller families. This provides a more realistic picture of desired reproductive goals that vary throughout the life course and with changing living conditions (Lee 1980). It also significantly improves the ability of reproductive desires to predict reproductive outcomes (Coombs 1979; Westoff 1981). 
The strength of respondents' fertility preferences was also included in previous surveys. Notably, Terhune and Kaufman (1973) did pairwise comparisons to construct the relative distance between preferences for specific numbers of children. However, they used these data to construct utility functions of offspring numbers. Their paper primarily influenced theoretically oriented research and micro-economic models of demand for children but was not taken into account by designers of surveys on fertility ideals. Though Pullum (1983) hypothesised that people might also be open to alternative fertility ideals, the question of how large the distances between a respondent's subsequent fertility ideals are remains to be answered. Moreover, scholars specialising on fertility ideals have not yet adequately clarified how many preferences should ideally be collected in surveys.

\subsection{Determinants of fertility ideals}

Fertility ideals vary across individuals and groups. Demographic research has made great efforts in trying to clarify the criteria which may explain these differences. Personality traits, personal values and lifestyle preferences have been shown to explain part of the differences (Miller 1994; Hakim 2003, p. 364 and Hakim 2004). Some personal values and lifestyle preferences tend to be more compatible with childbearing than others. Notably, individuals with traditional views on male and female roles generally have higher fertility ideals, whereas those striving for individualism and symmetrical roles of both sexes tend to have lower fertility ideals. While recent studies (e.g. those by Hakim) have started to use lifestyle indicators to capture differences, fertility studies (e.g. Coward 1981) traditionally use religion for this purpose.

Other studies emphasise the role of education in creating divergent fertility ideals. For the Netherlands, differences along these lines were identified by Liefbroer (2008) who showed that, at age 25, both men and women with lower education prefer to have fewer children than men and women with higher education. This relationship remains constant for men, but turns for women at age 30: At that point in time, the ideal number of children desired by lowly educated women surpasses that of highly educated women.

Findings on the effect of income on reproductive preferences are less clear, presumably because this variable also captures the effects of other determinants such as education, age and lifestyle preferences. Quality-quantity trade-offs may also play a role in blurring the pattern: Whereas higher incomes as such tend to raise offspring preferences, a higher valuation of the quality of offspring among high income earners may decrease their fertility ideals (Miller 1994).

A further cluster of determinants are life-cycle factors or 'demographics': marital status, marriage duration, the number of living children and the current age of individuals all shape fertility ideals (e.g. Pullum 1983). Marital status seems to play a role in particular if marriage is the normative context for 
childbearing or is perceived as a distinctive indicator for the stability of a relationship. In the case of the Netherlands, where other types of unions are not necessarily considered less stable than marriage (Van de Kaa 2001, p. 302), the impact of marital status on fertility ideals may be more limited than in other posttransitional societies. The number of children already present in a household is also positively associated with fertility ideals (Engelhardt 2004; Heiland et al. 2008). This largely reflects the outcome of selection effects, i.e. those who already have children are more likely to value children. The age of individuals, by contrast, is negatively associated with the ideal number of children: The higher a respondent's age, the more likely he or she is to have a lower ideal number of children (see Liefbroer 2009). Finally, gender matters: Men in the Netherlands tend to want smaller families than women do (Eurobarometer 2006, see Testa 2006, p. 30). It should, however, be pointed out that a recent study yielded mixed results for this issue (Liefbroer 2009) and that a stronger preference for children by females is not observed across all European countries (Testa 2006, esp. Figure 5).

\subsection{Our contribution}

For this study, we used an adapted version of Coombs-style questions in an online survey carried out in the Netherlands. To the best of our knowledge, this is the first time these questions were used in a European low fertility setting. As the instrument by Coombs provides information about the ideal number of children and alternative family sizes, we will concentrate on three research questions:

1) Do respondents' subsequently stated ideals yield information on their latent fertility preferences?

2) What are the determinants of ideal and alternative family sizes?

3) Can we gain insight into how many of the subsequent questions on fertility ideals should be included in fertility surveys to get optimal results?

As mentioned earlier, there tends to be a strong clustering on a preference for two children. In assessing the potential merits of including multiple ideals in fertility surveys, we primarily discuss this preference. In particular, we investigate whether including subsequent fertility preferences facilitates a better grasp of all people who report two as their ideal number of offspring. Do they have similar ideas when they are asked about alternative family size preferences or can we distinguish two subgroups among them, namely (i) a 'low two' of people who would prefer one child as the best alternative ideal to two and (ii) a 'high two' who see three children as their second best choice? 


\section{Data and methods}

The data used in this article come from an internet panel survey carried out within the framework of LISS (Longitudinal Internet Studies for the Social Sciences) set up by CentERdata, a research institute at Tilburg University. The panel consists of 8,000 individuals living in 5,000 households. It is based on a true probability sample of households drawn from the population register of Statistics Netherlands (CBS). Households that would have been unable to participate were given a computer and an internet connection. For these reasons, the survey arguably constitutes a representative sample of the Dutch population. Panel members are invited to participate in a 20-30 minute survey on a specific topic every month and are paid for its completion. Our fertility survey was carried out in August 2010 (first wave) and repeated in September 2010 (second wave). In this article, we only analyse results from the first wave.

In the first wave, 4,018 household members in the LISS panel were asked to participate in the survey. Of these, 2,591 accepted (overall response rate: 64.5 per cent) and filled in the questionnaire. Two-thirds of them $(\mathrm{N}=1,577)$ were asked to answer questions based on Coombs' design; 96 per cent agreed to do so $\left(\mathrm{N}=1,518\right.$; plus 59 refusals equals 1,577). ${ }^{2}$ Our final sample comprised 1,501 people. ${ }^{3}$ For each of our analyses, we used the maximum sample size that allowed us to include all variables considered in the specific analysis. As a result, sample sizes are not exactly the same between all of the tables and figures presented in our results section.

The questionnaire filled in by these respondents focused exclusively on the number of offspring they personally would like to have. To measure their preferences, we used Coombs' instrument but restricted it to the first to fourth preferences. Responses to questions on preferred family size are particularly sensitive to the 'wording' and/or 'formulation' of the question (Rasul 1993, p. 3). To ensure that respondents focused on ideals and not on intentions, our first question was formulated as follows: "We now turn to the topic of family and having children. We want to learn more about your preferences for different numbers of children. Can you tell us how many children you would ideally desire? If you already have children, we would still like to know how many children you would ideally like to have. The children can be born to you or adopted. What is your ideal number of children?" Respondents could select one of five possible answers: no children, one child, two children, three children and four or more children. In the follow-up question, they then had to choose between a

2 The other third $(\mathrm{N}=1,014)$ was asked to answer questions on fertility ideals based on the Terhune and Kaufman method (Terhune and Kaufman 1973). Of these, 976 accepted and 38 refused. This sample is now analysed in a separate study by Christoph Bühler.

3 Of the 1,518 respondents, we excluded 17 individuals who were not heads of household, spouses or partners of the head of household or a residing child of the head of household because of missing data. 
lower and a higher alternative to their first preference. This was done by addressing a hypothetical situation: "Imagine that, for whatever reason, you are not able to have $x$ children. ${ }^{4}$ In that case, would you rather want $x-1$ or $x+1$ children?" This pattern was repeated in similar follow-up questions asking respondents to choose between a higher and a lower alternative until they reached the lowest $(0)$ or the highest end of the scale (4 or more). These follow-up questions are almost identical with those used by Goldberg and Coombs (1963) and Coombs (1974). ${ }^{5}$ We should, however, note that Goldberg's and the Coombs' survey methodology differed from ours. They did extensive home interviews with fertile women only and started by asking them to imagine a situation where they could start their lives anew. Our first question, by contrast, did not invoke such a 'starting all over again' scenario.

The phrasing of the follow-up questions invited the respondents to consider an alternative to the personal ideal family size they had just indicated. However, as the survey we conducted was not an in-depth study we did not ask respondents for their reasons leading to these answers. As a result, we do not know to which extent respondents thought that all questions referred to the same concept of their personal fertility ideal. To some degree, the mental process of imagining an alternative ideal may have led respondents to incorporate more realism and their own circumstances in the answers given to the follow-up questions. This effect might have been amplified by the lack of explicit reference to the word 'ideal' in all but the first question. Hence the first answers might reflect more of an abstract ideal than the alternative choices do.

In addition to our series of questions on fertility ideals, we also asked respondents to indicate the strength of their preference for their first, second and third alternatives. In the case of the first preference, we asked: "To what extent do you prefer having children (first preference as indicated by respondent) over having ___ children (second preference as indicated by respondent)?". Respondents could choose between barely, a little, fairly much, very much and extremely much. The question was then repeated for second vs. third preference. In confronting respondents with this question, we followed Terhune and Kaufman (1973) who aimed at measuring relative strengths of preferences for ideal numbers of children by including a similar question in their survey. ${ }^{6}$

\footnotetext{
' $x$ ' is defined by the previous answer given by the respondent.

They asked: "Suppose you couldn't have that number, but had to choose between Which would you choose?" (Goldberg and Coombs 1963: 124). and

The actual phrasing of their question was: "Now tell me how much you prefer ( ) over ( ) by choosing your answer from the card. If it doesn't make much difference to you, you should say a or b. If it does make a difference to you, you should choose either c, $d$ or e." The answers offered to respondents were exactly the same as ours: (a) barely, (b) a little, (c) fairly much, (d) very much and (e) extremely much. See Terhune and Kaufman 1973: 608.
} 
The results obtained in our survey served as a basis for studying and discussing the methodological advantages of using a preference scale and measuring preference strength.

\section{Results}

\subsection{General results}

Table 1 summarises the distribution of primary fertility ideals among the male and female respondents in our survey. These figures are compared with those obtained in the 2006 Eurobarometer survey for the Netherlands, in which similar questions on fertility ideals were asked. ${ }^{7}$

The broad pattern across the two surveys is roughly the same. Respondents' personal fertility ideals are lower than those which, in their view, prevail in society at large. The comparison of the answer 'zero' clearly shows that childlessness is more often a personal ideal than a perceived societal one.

Table 1:

Distribution of fertility ideals (in per cent) in the LISS survey and Eurobarometer survey, Netherlands

\begin{tabular}{lcc|cc|rc}
\hline & \multicolumn{2}{c|}{ LISS $^{\mathbf{1 , 2}}$} & \multicolumn{2}{c|}{$\begin{array}{c}\text { Eurobarometer } \\
\text { Personal ideal }\end{array}$} & \multicolumn{2}{c}{$\begin{array}{c}\text { Eurobarometer } \\
\text { General ideal }\end{array}$} \\
\hline Fertility ideals & Men & Women & Men & Women & Men & Women \\
\hline Zero & 10.9 & 7.6 & 8 & 6 & 1 & 1 \\
One & 6.2 & 6.0 & 8 & 5 & 3 & 2 \\
Two & 59.7 & 55.8 & 47 & 47 & 53 & 45 \\
Three & 19.4 & 22.5 & 23 & 20 & 21 & 22 \\
Four or more & 3.8 & 8.0 & 7 & 17 & 5 & 6 \\
No ideal & $\mathrm{n} / \mathrm{a}$ & $\mathrm{n} / \mathrm{a}$ & 3 & 5 & 13 & 22 \\
Don't know & $\mathrm{n} / \mathrm{a}$ & $\mathrm{n} / \mathrm{a}$ & 4 & 2 & 4 & 2 \\
\hline Total & 100 & 100 & 100 & 100 & 100 & 100 \\
& $(\mathrm{n}=716)$ & $(\mathrm{n}=785)$ & $(\mathrm{n}=511)$ & $(\mathrm{n}=551)$ & $(\mathrm{n}=511)$ & $(\mathrm{n}=511)$ \\
\hline
\end{tabular}

Notes: (1) In LISS, the question asked was: "Can you tell us how many children you would ideally desire? (...). What is your ideal number of children?" (2) Age 15 to 54. (3) In the Eurobarometer survey, the question was:

"And for you personally, what would be the ideal number of children you would like to have or would have liked to have had?" This question was asked after the one on general fertility ideals. The answers were collected in 2006. (4) Age 15 and above. (5) "Generally speaking, what do you think is the ideal number of children for a family?"

Source: Testa 2006.

The main difference between our survey and the Eurobarometer is the percentage of people stating that their ideal number of children is two, which is

7 Note: In the Eurobarometer Survey, only the first ideal was asked for. 
somewhat higher in our survey. This might be due to the fact that our survey did not allow 'don't know' and 'no ideal' as answers. People with no defined ideals may simply have answered 'two children' in our survey, although we cannot verify this. With respect to preferences for four or more children we also observe a marked difference between the LISS and the Eurobarometer surveys. It is unclear how this should be accounted for. However, for the purposes of our article, it suffices to know that the results are roughly the same.

Figure 1 provides insights into the pathway of people's choices from their first to their last preference. Note that those whose first ideal was either 'zero' or 'four or more' children were not asked for further preferences and hence there is no information on the second and further choices of these groups. The results shed light on the popularity of each alternative option. Respondents had five options for their first choice (first column). In all other cases, they had only two options to choose between, i.e. one higher and one lower alternative to their previous preference.

The results presented in Figure 1 are of interest in several respects. First, the patterns displayed show that respondents are almost equally distributed across the low and high alternatives in several branches of the decision tree. There is no systematic pattern of an overwhelmingly dominant preference towards the lower or higher alternative, which could have pointed to a misunderstanding of our question. Respondents do not conceive of their first stated ideal as an upper limit on the number of children they might possible want to have. In some categories, more than half of the respondents opted for a second choice that exceeds the ideal number of children they stated in their first choice. It was also clear to respondents that they were asked about ideal, not actual fertility: Even among people with children, more than half of those whose first ideal was one child opted for having no children (rather than for having two) as a second choice. Respondents who had started off with lower ideals opted for the lowest alternatives more frequently than people with higher fertility ideals. This can be seen, for example, when comparing the third choices of people who answered that they want to have 2-3 children and those who answered they want 3-2. Respondents who stated three as their first ideal, opted for four children in 46 per cent of all cases when given a choice between four and one. By contrast, only 31 per cent of all those who ideally would like to have two children opted for four children. This corroborates hypotheses that preferences are internally consistent.

Our questions also provide insights into the acceptability of childlessness by making the order of preferences explicit. Around 9 per cent of all respondents in our survey answered that having no children was their personal ideal. Still, this figure may well be an underestimate of the actual 'no children' ideals as the respondents' answers may be skewed by the idea that answering 'zero' might be undesirable from a social viewpoint. ${ }^{8}$

Acceptability of childlessness is relatively high in the Netherlands. Sobotka and Testa 2008 found that respondents in the Netherlands had the most positive attitude towards childlessness 
A more expansive definition of support for childlessness may be gained by including those who stated that 'one child' was their primary and 'zero' their alternative fertility ideal. This hypothesis is supported by the relatively high percentage of people in this group ( 40 per cent) who indicated that one child was hardly preferably over zero children (see Table 3 below).

\section{Figure 1:}

Distribution of respondents according to their first choice and distribution of preferences among respondents' second, third and fourth alternative choices

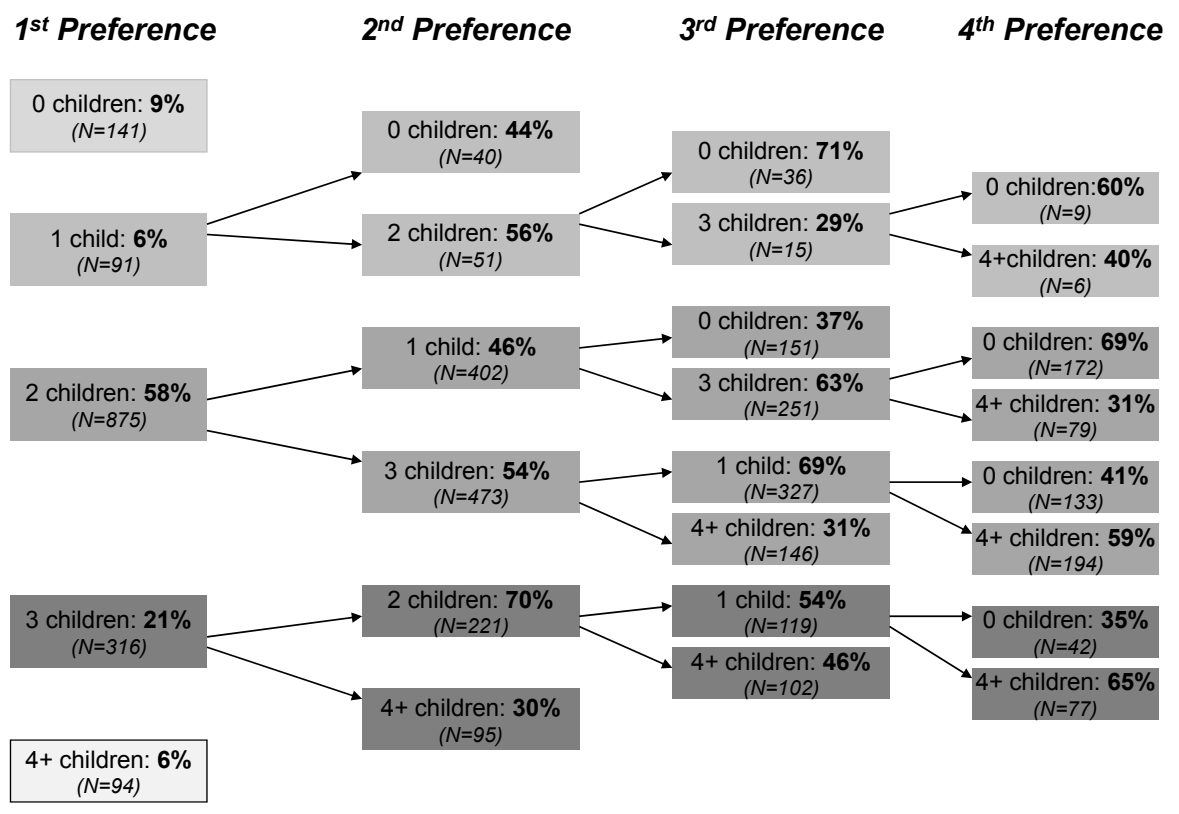

Note: The wording 'first, second, third and fourth preferences' is used here to distinguish the different follow-up questions. It was not used in the survey questions. Note that the interpretation of results for group of respondents indicating 'one' as first preference requires prudence: their number is small $(\mathrm{N}=91)$, which creates reliability problems when it is subdivided further.

Third, and corroborating findings from other surveys, we found a strong concentration around the 'two-child norm' with 58 per cent of all respondents

among 13 European countries. Dutch (and Flemish) people are particularly noteworthy regarding their views on the statement that "it is a duty towards society to have children": only 4.8 per cent of all Dutch women and 7.2 per cent of all Dutch men agreed or strongly agreed with the idea that childbearing is a social duty. This compares to 46 per cent of all women and 48 per cent of all men in neighbouring Germany (Table 9.1, p. 187). A paper on 25 European countries (Merz and Liefbroer 2010, Table 1) presented at the European Population Conference in 2010 found similar patterns with regard to the acceptance of childlessness. We may therefore assume that, in the case of the Netherlands, social undesirability would only mildly bias the percentage of zero fertility ideals. 
indicating this as their primary ideal. However, the follow-up questions reveal a clear split between the 'high two' (2-3) and the 'low two' (2-1) in this group. The results for those stating 'three' as their first choice are similar. The roughly even sizes of the groups of 'ascenders' and 'descenders' suggest that there is a continuum of ideals in populations rather than a pronounced segmentation of groups with clearly distinct ideals.

\subsection{The value of alternative preferences: amplifying differences}

We argue that information on alternative preferences adds depth to our understanding of different fertility ideals. Importantly, second and further choices seem to amplify differences between groups. This can be illustrated by comparing the results of measuring one single preference with those including first and second preferences. Our examples relate to gender and education differences, respectively. Because the number of cases became too small for fourth preferences, we excluded them in the subsequent discussion which focuses on respondents' first to third preferences.

Figure 2 shows the information delivered by first preferences only and the knowledge provided by including second preference information. As we can see in Figure 2a, women's fertility preferences tend to be higher than those of men. However, gender differences become much more pronounced when we also take into account males' and females' second choices (Figure 2b). Men answering 'two children' as their ideal tend to opt for 'or one' as their second choice much more frequently than women, who are more inclined to say 'or three'. Those stating 'one child' as their first choice follow a consistent pattern: women in this group are more likely to choose 'or two children' and men more likely to choose 'or zero children' as their second preference. Including second preferences thus amplifies existing differences in fertility preferences. It shows the extent of bargaining that might take place in households in which the ideals between men and women seem to be identical at first sight. Moreover, this method illustrates that the discrepancy between ideal and achieved fertility apparently is larger for women, but smaller for men, than single ideals suggest. The stronger convergence between men and women regarding their first stated ideals may be due to the fact that respondents tend to take into account their partners' desires. This would lead men to raise their ideals and women to lower them. We find, in other words, that adding second preferences considerably enriches information on people's preferences.

With regard to education, the inclusion of second preferences illustrates that a similar pattern of stronger differences underlies first preferences (Figure 3). Fertility preference studies in which respondents only had to state one single ideal already found a difference between people with different educational backgrounds: Individuals with higher education tend to have higher fertility ideals 
(Liefbroer 2008; Heiland et al. 2008). Second choices make the divergence along educational lines even clearer: Respondents with higher education who chose 'two children' in the first instance were much more likely to consider three children as an ideal than respondents with a lower educational background. If we assume that respondents think of second preferences as 'what if' scenarios, the split according to education levels might hint at the role of financial affordability and the pressures of combining work and child care as factors affecting fertility ideals. Again, adding a second preference amplifies the differences observed.

\section{Figure 2:}

Integrating second preferences by sex: amplification of differences

a) First preferences
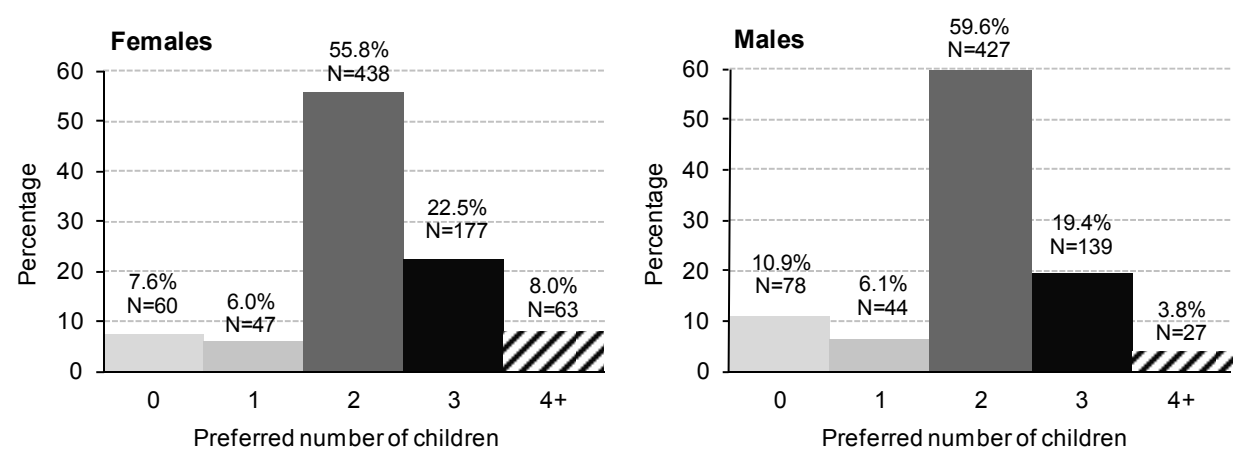

b) Combined first and second preferences; normalised
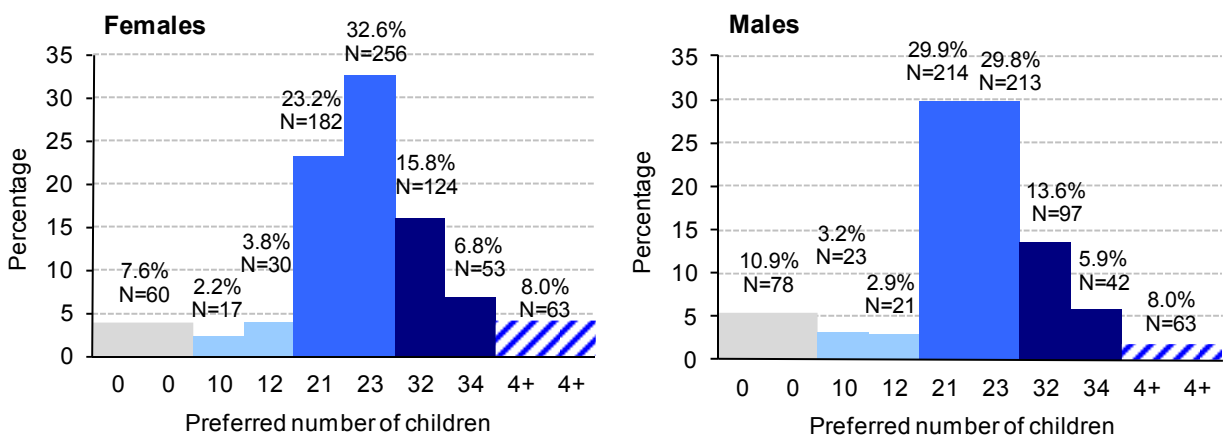

Note: There are no second preferences available for those answering either zero or four as their first choice. In part b) of the Figure, we divided the percentage of people preferring zero or four children over two bars in order to make the area of the 0 and 4 responses comparable to the area of the other 'divided' responses. To obtain the comparable percentages with the upper panels, the heights of the 0 and $4+$ categories need to be doubled: i.e. the total percentage of people preferring no children as a first choice is $3.8 \% \times 2=7.6$ per cent. The numbers on the $\mathrm{X}$-axis refer to the first and second preferences.

Interestingly, our results on the association between education and fertility contrast with earlier findings. These suggested that fertility differentials by education were narrowing in the Netherlands (Van de Kaa 2001, p. 319). To the 
extent that fertility ideals are linked with fertility outcomes, our results suggest that these converging trends have come to a halt. It is also possible, however, that first choices simply underestimate the differences between groups. Second preferences furthermore show that first preferences should not be understood as minimum desires for offspring. For example, among the people with less than university education whose ideal was 'one child' in the first instance, only about half opted for 'two children' as an alternative. The other half of them lowered their ideal and preferred no children as a second ideal.

Figure 3:

First only vs. first and second preferences by education a) First preferences
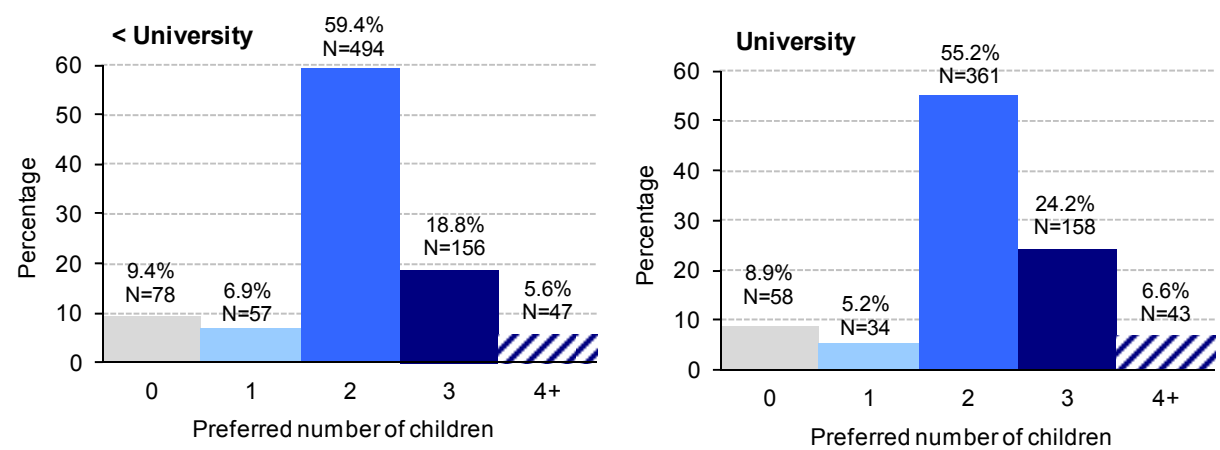

b) Combined first and second preferences; normalised
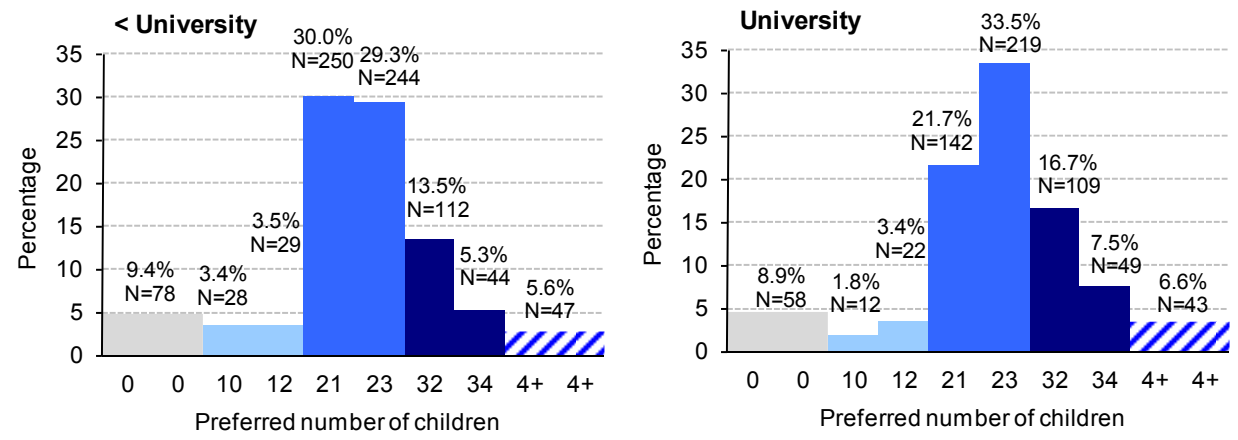

Note: see note in Figure 2.

Encouraged by these results, we also investigated third preferences. Regarding sex, we found that men were again more inclined to choose the lower alternatives than women when asked about their third preference. Third preferences thus confirmed the differential patterns between men and women as revealed by second preferences. The only notable exception to this trend occurred within the group whose first and second choices were 1-2 children. The women in this group were more likely than men to favour having no offspring at all when 
faced with a subsequent choice between zero and three. Men more often opted for the higher alternative. However, this result may well be spurious since the group only comprised 51 individuals and the further subdivisions into three vs. no children and males vs. females lowered the numbers even further.

Including the third preference according to level of education presented a more complicated picture. Figure 4 shows the effect of including the third preference by education. In this case, the trend observed for second preferences is not continued into third preferences: whereas the highly educated tended to opt for higher alternatives when offered a second choice, in their third choices they instead tend to opt for the lower alternatives more often than respondents with low education. Their less educated peers also showed a preference towards opting for the lowest alternative, but the effect among respondents with university education was more pronounced. This is particularly obvious when comparing the subsequent choices of lower and higher educated groups who had opted for '2-3 children' as first and second choices. Interestingly, preference patterns between respondents with non-university and university education are thus reversed between the second and third preferences. We suggest that this reversal might be rooted in the higher opportunity costs of having a large number of children for people with high education. Since our survey did not include any questions revealing respondents' motivations for choosing between alternatives, however, other possible explanations remain.

\section{Figure 4:}

Integrating third preferences by education: reversing differential trends; normalised
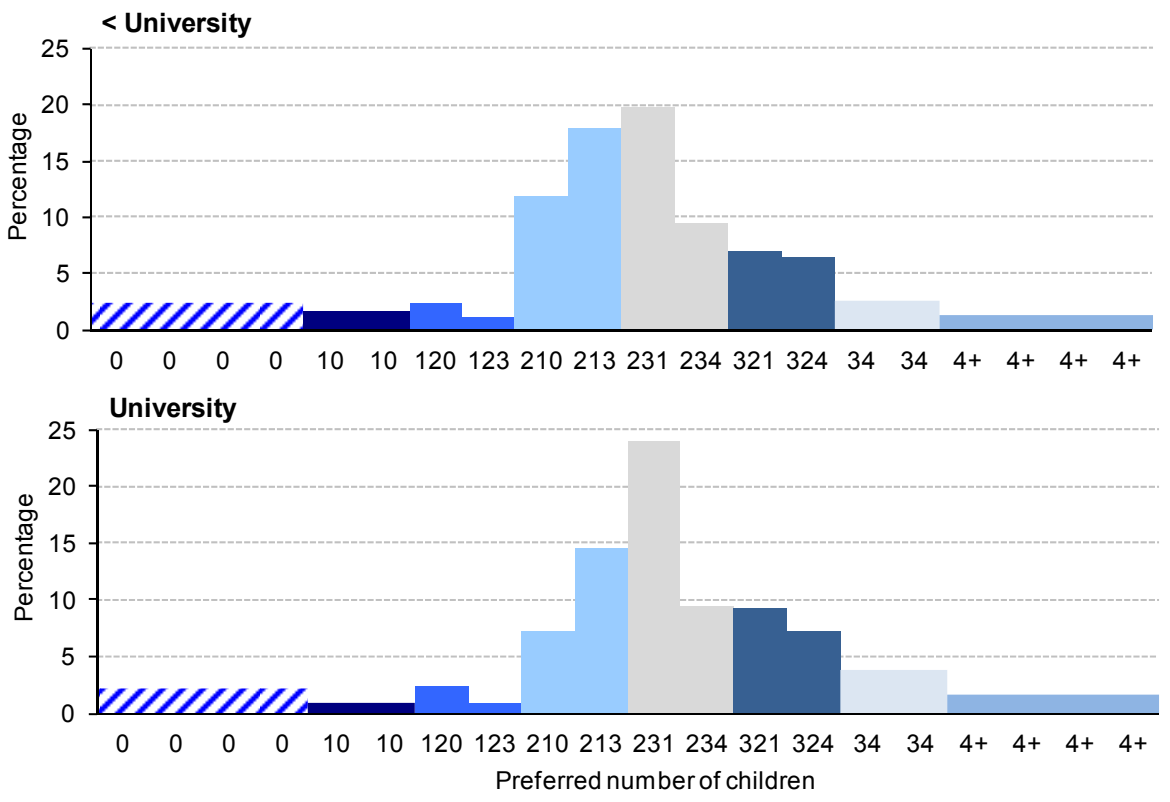

Note: See note in Figure 2. 
Our current exploration of third preferences suggests that they can in some cases reveal even more complex dynamics underlying fertility preferences dynamics that might be worth investigating further. The example of sex differences, however, clearly shows that such is not necessarily the case: here, we found that the relative net gain of including third preferences was smaller than that of including second preferences. Third preferences added less to prior knowledge than second preferences did.

\subsection{Strength of fertility preferences}

After the respondents had answered all follow-up questions in our survey, we asked them to state the degree of their preference for their first vs. their second preference and for their second vs. their third preference. The results suggest that people are quite open to their 'second choices' and not overly attached to the ideal number of children they stated as their first choice (see Table 2). A surprisingly high percentage of all respondents said that they hardly had any preference for their first over their second choice. Overall, only around one fifth of all respondents indicated that they felt strongly or very strongly about their first choice. These results may reflect a genuine absence of clear preferences. However, the interchangeability of first and second preferences may also be due to the fact that respondents are well aware that their fertility ideals and the chances to realise them depend on circumstances (Schaeffer and Thomson 1992). Some of the qualitative comments on the survey confirm this impression, as respondents emphasised their difficulty to decide on a number and pointed to the friction between ideals and their realisation. ${ }^{9}$

Feelings about having children and the ideal number of offspring are also affected by the partner's desires. A high willingness to exchange the second for the first preference may reflect a situation in which joint preferences of partners differ from their individual preferences (Voas 2003, p. 638-639 on the effect of partner desires on stated fertility desires). In low fertility settings, ideal fertility tends to be downgraded to fit the lowest offspring desires in the partnership. In psychology, regret regulation theory predicts that people may delay a decision or aim to increase the reversibility of a decision in order to avoid or mitigate anticipated regret in contexts in which uncertainty affects the outcomes of choices (Zeelenberg and Pieters 2007, p. 11-13). While this theory focuses primarily on consumptive decisions rather than on ideals, the openness towards alternative numbers of offspring that respondents display fits well into this theoretical framework. Not focusing too strongly on one single number of children as an

9 Respondents at different stages in their life course pointed out this problem: those with children emphasized the difficulty of stating ideals retrospectively when they already knew what their current situation was like, whereas respondents without children stated that they found the questionnaire very clear, but the suggestion that one could simply choose one's personal ideal number of children seemed not very realistic to them. 
ideal is a form of choice postponement, which can avoid or weaken negative emotions when things turn out differently.

When interpreting the distributions in Table 2, a general point to consider is that answers may be affected by the fact that the questions on the strength of respondents' fertility preferences were asked at the end of the survey when they had already answered up to three follow-up questions. Undefined answers may therefore reflect a certain fatigue with answering questions, although we find no indications for this in the respondents' qualitative comments on the survey design.

Table 2:

Distribution of strength of preference: first vs. second and second vs. third preference

\begin{tabular}{|c|c|c|}
\hline Strength of preference & $1^{\text {st }}$ vs. $2^{\text {nd }}$ preference & $2^{\text {nd }}$ vs. $3^{\text {rd }}$ preference \\
\hline Hardly any & $12.7 \%$ & $11.7 \%$ \\
\hline Small & $30.5 \%$ & $29.6 \%$ \\
\hline Moderate & $38.2 \%$ & $35.4 \%$ \\
\hline Large & $15.1 \%$ & $19.2 \%$ \\
\hline Extremely large & $3.5 \%$ & $4.1 \%$ \\
\hline Total & $100.0 \%$ & $100.0 \%$ \\
\hline Mean ${ }^{\mathrm{a}, \mathrm{b}}$ & 2.66 & $2.74^{*}$ \\
\hline $\mathrm{N}$ & 1272 & 1136 \\
\hline $\mathrm{N}$ of missing values & 229 & 365 \\
\hline
\end{tabular}

Notes: (a): Mean value obtained by assigning the values 1 to 5 to the five different response categories. A higher value indicates a stronger preference for the number of children stated first. We computed the mean as a summary measure even though the original variable was ordinal and we cannot be certain that the distances between adjacent categories are the same. (b): An asterisk indicates that the means are statistically different at the .05 level. In this case, we used a one-sample t-test.

Table 3 compares the strength of preference for first, second and third choices. It shows that there are no substantial differences between respondents with higher or lower fertility ideals in their attachment to ideals. The only exception were respondents who said they wanted 3-2 children; their preferences were less marked. It is remarkable that the group most attached to its first ideal are those who opted for '2-3 children'. Only 35 per cent of them said they had hardly any or only a small preference for their first choice and they were relatively definite in preferring two over three children. People whose ideal was three children, by contrast, were fairly happy to accept two as an alternative: 65 per cent found that having two would hardly make a difference to them as compared to having three. The computed mean values in Table 3 show an interesting pattern, namely that respondents were consistently more open towards accepting a 'second choice' that involved a lower ideal than willing to attach to an ideal that was higher than their first choice.

How does the relatively small distance between respondents' first and second preference compare to their strength of preference for their second vs. third preference? Are respondents equally open to substitute their second ideal by their 
third ideal? Table $3 \mathrm{~b}$ shows that this is not the case. Respondents indicated a stronger preference for their second choice. In other words, they were less willing to settle for their third ideal. The higher value of the mean for the second choice indicates that third preferences are not only less important because they are stated third; they are also further away from the second preferences than the second preferences are from the first.

Table 3:

Respondents' strength of preference: first, second and third preference 3a) First versus second preference (in per cent)

\begin{tabular}{lcccrcr}
\hline $\begin{array}{l}\text { Preference } \\
\text { for the first } \\
\text { vs. the second } \\
\text { choice }\end{array}$ & $\begin{array}{c}\text { Hardly any } \\
\text { (1) or small } \\
\text { preference (2) }\end{array}$ & $\begin{array}{c}\text { Moderate } \\
\text { preference } \\
(\mathbf{3})\end{array}$ & $\begin{array}{c}\text { Strong (4) or } \\
\text { extremely } \\
\text { strong (5) } \\
\text { preference }\end{array}$ & Total & $\begin{array}{c}\text { Mean } \\
\text { b. }\end{array}$ & $\begin{array}{c}\text { N of } \\
\text { cases }\end{array}$ \\
\hline $1 \rightarrow 0$ & 40 & 38 & 23 & 101 & 2.63 & 40 \\
$1 \rightarrow 2$ & 43 & 29 & 27 & 99 & 2.80 & 51 \\
$2 \rightarrow 1$ & 42 & 38 & 20 & 100 & 2.69 & 396 \\
$2 \rightarrow 3$ & 35 & 43 & 21 & 99 & 2.81 & 469 \\
$3 \rightarrow 2$ & 62 & 30 & 9 & 99 & 2.30 & 221 \\
$3 \rightarrow 4$ & 46 & 37 & 17 & 100 & 2.57 & 95 \\
\hline
\end{tabular}

3b) Second versus third preference (in per cent)

\begin{tabular}{lcccccc}
\hline $\begin{array}{l}\text { Preference } \\
\text { for the first } \\
\text { vs. the second } \\
\text { choice }\end{array}$ & $\begin{array}{c}\text { Hardly any } \\
\text { (1) or small } \\
\text { preference (2) }\end{array}$ & $\begin{array}{c}\text { Moderate } \\
\text { preference } \\
\mathbf{( 3 )}\end{array}$ & $\begin{array}{c}\text { Strong (4) or } \\
\text { extremely } \\
\text { strong (5) } \\
\text { preference }\end{array}$ & Total & $\begin{array}{c}\text { Mean } \\
\text { bo, }\end{array}$ & $\begin{array}{c}\text { N of } \\
\text { cases }\end{array}$ \\
\hline $12 \rightarrow 0$ & 44.4 & 33.3 & 22.2 & 100 & 2.72 & 36 \\
$12 \rightarrow 3$ & 46.6 & 20.0 & 33.3 & 100 & 2.67 & 15 \\
$21 \rightarrow 0$ & 36.7 & 32.0 & 31.3 & 100 & 2.87 & 148 \\
$21 \rightarrow 3$ & 37.9 & 39.1 & 23.0 & 100 & 2.76 & 248 \\
$23 \rightarrow 1$ & 54.0 & 38.0 & 8.0 & 100 & $2.45^{*}$ & 324 \\
$23 \rightarrow 4$ & 33.8 & 28.3 & 38.0 & 100 & $2.96^{*}$ & 145 \\
$32 \rightarrow 1$ & 23.6 & 37.8 & 38.7 & 100 & $3.18^{*}$ & 119 \\
$32 \rightarrow 4$ & 45.1 & 33.3 & 21.5 & 100 & $2.67^{*}$ & 102 \\
\hline
\end{tabular}

Notes: (a) and (b): See Table 2. Note, however, that in this case we used a one-way comparison of means. We used the post-hoc Games and Howell's pairwise comparisons test, which can be applied when variances are unequal. The results reported here thus pertain to the comparison within groups, i.e. within groups that share the first preference(s). For example, we found that the mean preference for the category 32-1 is different from that of category $32-4$ at the 0.05 level.

Comparing the strength of preferences also provides insights into the relative advantages and merits of including only second but not subsequent additional preferences in surveys on fertility ideals. Whereas the Coombs advocated including a high number of subsequent preferences, we feel that there is much to be gained by adding only a second preference. Second preferences already provide a lot of information that surveys asking for a single preference cannot yield. At the same time, they require only a limited expansion of current survey 
designs and avoid the disadvantages associated with including third and subsequent preferences. Moreover, working with up to four preferences may become analytically complex and requires large sample sizes to ensure sufficiently large cell numbers. In addition, the strength of preference distributions shows that second preferences are more valuable than third preferences. Although additional preferences might still improve datasets, we think that including two preferences already offers high relative gains as compared to including only one single point estimate.

\section{Discussion}

\subsection{Advantages of questions on fertility ideals}

Irrespective of whether preferences relate to children, cars, political parties or consumer goods, they are usually not fixed and discrete but vary within certain limits. By measuring a hierarchy of reproductive preferences rather than a single point estimate, we are better able to capture the range of possibilities an individual may choose from. This is a great strength of the method we used.

Moreover, the survey design enables researchers to measure sensitivity to variation. Our respondents' answers reveal that the psychological distance between specified numbers of children is hardly the same for all individuals. Whereas some respondents are extremely attached to their first preference, others - many in fact - are fairly to very willing to switch to alternative preferences if conditions change. This willingness to substitute one ideal by another under different circumstances helps us understand why so many people seem to deviate from their stated ideal in low fertility societies. It also questions the extent to which respondents perceive such unmet fertility desires as real loss. This finding is of interest to policy makers as it shows how flexible and adaptive Dutch citizens are when it comes to fertility desires. In this regard, it should also be underlined that Dutch respondents are consistently more open to an alternative that entails lowering their ideal fertility than to one that would involve reproducing beyond their first ideal number of offspring. Future studies may reveal whether there are differences between countries in the extent to which people are open to second choices, whether they prefer to go below or above their ideals and how the latter relate to social systems and macro-level indicators such as net incomes and population density. While questions on fertility desires cannot substitute questions on fertility intentions, they could be included as an additional explanatory variable when exploring the link between intentions and behaviour.

Measuring first and second choices with Coombs' instrument also enhances insight into the acceptability of childlessness among respondents. The prevalence of social norms which deplore childlessness or having just one child may lead respondents to avoid these answers and give a socially desirable answer instead, 
even if this is not their personal ideal. Particularly when pro-natalist norms are strong (which is the case in many countries) personal preferences for childlessness may arguably better be revealed by second choices than by first choices. In our survey, we did not observe a strong tendency towards avoiding the answers 'zero' or 'one child', but since the Netherlands is among the European countries with the highest acceptability of childlessness (Merz and Liefbroer 2010), the relatively minor effects observed in the Netherlands are bound to be unrepresentative.

In sum, from a qualitative perspective including alternative family sizes and strength of preference in studies on fertility preferences offers several benefits. Our findings also suggest that the relative gain of adding one single extra preference, i.e. a second choice, is high. Whereas first and second choices were relatively interchangeable, respondents reported a stronger motivation to avoid their third choice. This result points to an additional strength of the method, namely its smooth implementation and application. Questions on fertility ideals are easy and cheap to administer; it is relatively simple to translate them into other languages (also thanks to the fact that questions on fertility desires have already been used in many countries) and respondents seem to experience no major difficulties in answering them.

\subsection{Limitations of questions on fertility ideals}

The most evident limitation of Coombs' question is that it forces people to state a first preference and channels them into a tree-like decision-making process based on their first reply (see Figure 1 above). The options respondents were offered entirely depended on their previous answers, so that they were guided into a pathway without an 'erase and rewind' option. The alternative method of pairwise comparison by Terhune and Kaufman (1973) does not force people into stating such a first preference. It guides respondents through all possible combinations of family sizes within a predefined range, asking them to choose a number of children for each case. However, in this case collecting all the information needed for such a hierarchy of desired family sizes is more complex. Another consequence of using a decision tree is that, in the current design, our Coombs' question does not provide any additional information about people whose first preference is either zero or four. We are therefore unable to tell how fixed their preferences are and what alternatives they might consider. This is a serious limitation.

Our questionnaire at the start explicitly referred to respondents' personal ideals and asked them to only report their personal preferences. However, when respondents were subsequently asked to state 'alternative ideals', they might have shifted from considering their own preferences regardless of their own circumstances to considering their own preferences given their own circumstances. Without in-depth interviews, we simply remain in the dark as to 
what constraints respondents had in mind when answering the questions (see Rasul 1993, p. 3). Alternative ideals may therefore capture something slightly different from the first ideal. On the bright side, if alternative ideals reflect a higher degree of realism they may be better predictors of behaviour.

\subsection{Next steps}

We aim to pursue several of the findings obtained in this initial study in more detail. At the substantive level, multivariate analysis of the co-variates of fertility preferences will refine our understanding of the types of individuals connected to different hierarchies of reproductive preferences. Understanding the motivations for second preferences will enhance insights into the trade-off mechanisms underlying fertility preferences: How and why do people get to be 'descenders' or 'ascenders' when it comes to decisions about alternative childbearing preferences?

At the methodological level, two issues merit further attention. First, it is important to establish how our results compare with those provided by the Terhune and Kaufman fertility survey method, which uses pairwise comparisons of all combinations of family size between zero and four. Another issue is the question of how much people's ideals fluctuate within a short period of time. We intend to investigate this issue by comparing the current first wave of results with those of a second wave (collected one month later). Follow-up studies could also provide deeper insight into the predictive validity of combined first and second choices by showing in how many cases the actual number of offspring is below or above the first two ideals. We expect that there will be few such cases and that including first and second preference questions in surveys on fertility desire substantially enhances predictability levels.

\section{Conclusion}

In studies on fertility ideals, the fact that survey methodology could be improved is an often heard complaint. We therefore chose to do a survey of randomly selected participants $(\mathrm{N}=1,501)$ in the Netherlands, which was implemented as part of the LISS panel survey. We wanted to study the potential offered by measuring alternative fertility preferences for improving the survey methodology of demographers interested in fertility ideals. We found that asking respondents about their alternative fertility preferences in addition to their first stated ideal improves the quality and quantity of information gained in several respects.

Our survey confirms earlier hypotheses that "the researcher's focus on a single number as the ideal may (...) fail to reflect a weakness in that stated preference" (Pullum 1983) because "alternatives, although less preferred, may also be acceptable". Our survey design revealed that, in fact, respondents are 
surprisingly flexible and display a high degree of openness towards alternative ideals. This new finding has important implications both for demographic researchers and policy makers. We therefore recommend that future survey protocols adapt the standard design to collect information on alternative preferences and on the strength of people's ideals. While the Coombs were strong proponents of including information on four to six preferences in fertility preference analyses, we find that the relative gain of simply including the second preference is already high. Third preferences seem less salient because they are further away from the second preferences than the second are from the first. By adding one single question on alternative ideals to the design and another one on the strength of people's preferences, fertility studies can obtain significant extra value at little extra cost.

Including an alternative preference in survey designs also provides tools for differentiating subpopulations with identical first ideals. This is particularly useful for the large group of individuals who state two children as their ideal. Information on the further preferences of this group identifies 'low two' and 'high two' respondents, who are systematically distinguishable by characteristic covariates. We illustrated this by focusing on gender and education differences, which are amplified when second preferences are taken into account. Inclusion of alternative preferences reveals profiles connected to specific fertility ideals more clearly than isolated first preferences do. In other words, measuring reproductive desires by using a hierarchical methodology documents latent desires for smaller or larger families and thus is a more refined and adequate measure of fertility preference than methods hitherto employed. The added value of subsequent questions is particularly evident in the case of low fertility preferences that may not match the ideals prevailing in the respective society. In such cases, respondents may be tempted to inflate their ideal number when asked about their first preference: Their ordering of subsequent choices and their strength of preference for initial choices is revealing.

The results of our analysis show that preferences tend to be internally consistent: Respondents do not randomly select different pathways but make consistent choices. They understand that they are expected to consider both lower and higher alternatives to their original ideal number of children: We observed no bias towards lower alternatives that would raise doubts on the survey methodology.

Future research shall reveal whether or not using preference orders improves the power of reproductive preferences as predictors of reproductive outcomes. According to the theory, this will be the case if second choice ideals include more realistic notions. Alternative preferences may indicate the direction of change in decision-making when respondents are faced with changed conditions that prevent them from fulfilling their ideal choice. This hypothesis was empirically tested by Coombs in a developed world setting in 1974. Her study linked scaled fertility preferences to fertility outcomes. Fertility outcomes consistently diverged 
for women with the same ideal family size but different second and further preferences: At all parities, women with higher alternative preferences had more births than women with lower alternative preferences (Coombs 1974, p. 597f). The net effect of higher vs. lower second and further preferences amounted to a difference of about 0.5 children. This suggests that alternative preferences may indeed be good indicators of the direction fertility behaviour may take when trade-offs with other preferences need to be made. It urges further empirical testing in a current low-fertility setting.

\section{Acknowledgements}

The authors would like to thank Anne-Kristin Kuhnt (MPIDR) for her contributions to the literature research for this article. They are also grateful to the researchers at the CentERdata Institute in Tilburg, the Netherlands, for carrying out the survey in the LISS online panel. Participants of the December 2010 VID/REPRO conference on reproductive decision-making in Vienna provided useful comments on the research for this article. Saskia Hin also wants to thank Domantas Jasilionis (MPIDR) for his helpful advice.

\section{References}

Ahmed, N.R. 1981. Family size and sex preferences among women in rural Bangladesh. Studies in Family Planning 12.3, 100-109.

Ajzen, I. 1991. The theory of planned behaviour. Organizational Behaviour and Human Decision Processes 50, 179-211.

Axinn, W.G., M.E. Clarkberg and A. Thornton 1994. Family influences on family size preferences. Demography 31(1): 65-79.

Bongaarts, J. 2001. Fertility and reproductive preferences in post-transitional societies. Population and Development Review Supplement 27: 260-281.

Bühler, C. 2010. Measuring preferred family size. Unpublished manuscript. Rostock and Hannover: Max Planck Institute for Demographic Research and Leibniz University.

Coombs, L. 1974. The measurement of family size preference and subsequential fertility. Demography 11(4): 587-611.

Coombs, L. 1979. Reproductive goals and achieved fertility: a fifteen-year perspective. Demography 16(4): 523-534.

Coward, J. 1981. Ideal family size in Northern Ireland. Journal of Biosocial Science 13(4): 443-454.

Dey, I. and Wasoff, F. 2010. Another child? Fertility ideals, resources and opportunities. Population Research and Policy Review 29: 921-940.

Engelhardt, H. 2004. Fertility intentions and preferences: effects of structural and financial incentives and constraints in Austria. Working Paper 2004(02), Vienna: Vienna Institute of Demography. http://www.oeaw.at/vid/download/WP2004_2.pdf 
European Commission 2005. Confronting demographic change: a new solidarity between the generations. Green Paper COM 2005(94), Brussels: Communication from the Commission of the European Communities.

Gallup, G. and C. Robinson 1938. American Institute of Public Opinion surveys, 19351938. Public Opinion Quarterly 2(3): 373-398.

Goldberg, D. and C.H. Coombs 1963. Some applications of unfolding theory to fertility analysis. In Emerging Techniques in Population Research, Milbank Memorial Fund, 105-129. New York: Milbank Memorial Fund.

Goldstein, J., W. Lutz and M.R. Testa 2003. The emergence of sub-replacement family size ideals in Europe. Population Research and Policy Review 22: 479-496.

Hakim, C. 2003. A new approach to explaining fertility patterns: preference theory. Population and Development Review 29(3): 349-374.

Hakim, C. 2004. Childlessness in Europe: summary of research results for the Economic and Social Research Council. Swindon: Economic and Social Research Council.

Hakim, C. 2011. Women's lifestyle preferences in the $21^{\text {st }}$ century: implications for family policy. In The future of motherhood in Western societies, ed. G. Beets, J. Schippers and E. R. te Velde, 177-195. The Netherlands: Springer.

Heiland, F., A. Prskawetz and W.C. Sanderson 2008. Are individuals' desired family sizes stable? Evidence from West German panel data. European Journal of Population 24: 129-156.

Knodel, J. and V. Prachuabmoh 1973. Desired family size in Thailand: are the responses meaningful? Demography 10(4): 619-637.

Lee, R.D. 1980. Aiming at a moving target: period fertility and changing reproductive goals. Population Studies 34(2): 205-226.

Liefbroer, A. 2008. Kinderwens wordt in de loop van het leven bijgesteld. Demos 24(3): 4-6.

Liefbroer, A. 2009. Changes in family size intentions across young adulthood: a lifecourse perspective. European Journal of Population 25(4): 363-386.

Lightbourne, R.E. and A.L. MacDonald 1982. Family size preferences. World Fertility Survey Comparative Studies Cross National Surveys 14. United Kingdom: Charlesworth Ltd.

Merz, E.-M. and A.C. Liefbroer 2010. Attitudes about voluntary childlessness across Europe: the role of individual and cultural factors. Paper presented at the European Population Conference 2010, Vienna, 1-4 September 2010. http://epc2010.princeton.edu/download.aspx?submissionId=100717

Miller, W.B. 1994. Childbearing motivations, desires, and intentions: a theoretical framework. Genetic, Social and Psychology Monographs 102(2): 225-258.

Morgan, S.P. 2001. Should fertility intentions inform fertility forecasts? In Proceedings of U.S. Census Bureau Conference: The Direction of Fertility in the United States, ed. U.S. Census Bureau, 151-184. Washington D.C., USA. http://www.copafs.org/UserFiles/file/reports/The\%20Direction $\% 20$ of $\% 20$ Fertility $\% 2$ 0in $\% 20$ the $\% 20$ United $\% 20$ States.pdf\#page $=165$

Perugini, M. and R.D. Bagozzi 2001. The role of desires and anticipated emotions in goaldirected behaviours: broadening and deepening the theory of planned behaviour. British Journal of Social Psychology 40: 79-98.

Philipov, D. and L. Bernardi. Forthcoming. Reproductive decisions: concepts and measurement in Austria, Germany and Switzerland. Comparative Population Studies. 
Pullum, T.W. 1983. Correlates of family size desires. In Determinants of fertility in developing countries: a summary of knowledge, ed. R.A. Bulatao, R.D. Lee, P.E. Hollerback and J. Bongaarts, 278-298. Washington D. C.: National Academy Press.

Rasul, A. 1993. Fertility preference: a study of some basic concepts and considerations. The Journal of Family Welfare 39(1): 24-32.

Schaeffer, N.C. and E. Thomson (1992) The discovery of grounded uncertainty: developing standardized questions about strength of fertility motivation. In Sociological Methodology 22, ed. Marsden, P.V, 37-82. Oxford: Blackwell.

Sobotka, T. and M.R. Testa 2008. Attitudes and intentions toward childlessness in Europe. In People, population change and policies. Lessons from the Population Policy Acceptance Study, Vol. 1: Family change, ed. C. Höhn, D. Avramov and I.E. Kotowska, 177-211. The Netherlands: Springer.

Stoezel, J. 1954. Les attitudes et la conjoncture démographique: la dimension idéale de la famille. In Proceedings of the World Population Conference 1954 (Rome), Vol. 6, ed. United Nations, 1019-1035. New York: United Nations.

Terhune, K.W. and S. Kaufman 1973. The family size utility function. Demography 10(4): 599-618.

Testa, M.R. 2006. Childbearing preferences and family issues in Europe. Special Eurobarometer 253/Wave 65.1, TNS Opinion \& Social. http://ec.europa.eu/public_opinion/archives/ebs/ebs_253_en.pdf

Testa, M.R. and L. Grilli 2006. The influence of childbearing regional contexts on ideal family size in Europe. Population 61(1-2):109-138.

Trent, R.B. 1980. Evidence bearing on the construct validity of "ideal family size". Population and Environment 3(3-4): 309-324.

Van de Kaa, D. 2001. Postmodern fertility preferences: from changing value orientation to new behaviour. Population and Development Review 27: 290-331.

Voas, D. 2003. Conflicting preferences: a reason why fertility tends to be too high or too low. Population and Development Review 29(4): 627-646.

Westoff, C.F. 1981. The validity of birth intentions: evidence from U.S. longitudinal studies. In Predicting fertility: demographic studies of birth expectations, ed. G.E. Hendershot and P.J. Placek, 51-59. Lexington: Lexington Books.

Zeelenberg, M. and Pieters, R. 2007. A theory of regret regulation. Journal of Consumer Psychology 17(1): 3-18. 